\title{
Plantão Psicológico: Ficções e Reflexões
}

Psychological Duty: Fictions and Thoughts

Guardia Psicológica: Ficciones y Reflexiones

Juliana Oliveira Breschigliari

Universidade de São Paulo

Giovana Telles Jafelice

Universidade Federal de São Paulo

http://dx.doi.org/10.1590/1982-3703000112014 
Resumo: O presente texto tematiza uma experiência de plantão psicológico que apresentou em seu desencadeamento reflexões pertinentes à elaboração do sentido específico dessa modalidade na formação profissional em Psicologia, com destaque à fronteira com a Psicoterapia. É apresentado o contexto institucional do Serviço de Aconselhamento Psicológico da USP, no qual se insere a experiência, bem como a narrativa do atendimento propriamente dito e comentários que articulam vivência clínica e reflexões teóricas no âmbito da abordagem centrada na pessoa e na fenomenologia existencial. São destacados aspectos percebidos como fundamentais no fazer do plantonista, tais como: a sustentação da postura de acolhimento e de pesquisa com relação aos sentidos da queixa; o olhar atento ao modo como o cliente se apresenta desde a chegada, no decorrer e desfecho do percurso de plantão; e o investimento na construção de uma relação de confiança. Por fim, o texto retoma e tematiza a noção de demanda que subjaz à proposta de plantão e explora a partir da experiência das personagens envolvidas - cliente, plantonista e supervisora - um dos paradoxos não diretivos presente, de acordo com Max Pagés (1976), na relação de ajuda psicológica, qual seja, o da identificação-diferenciação entre terapeuta e cliente.

Palavras-chave: Plantão psicológico. Formação do psicólogo. Terapia não diretiva. Fenomenologia existencial.

Abstract: This work reports some experiences occurred in a department of psychological duty and some considerations about this specific modality of attention, taking into consideration the education of future psychologists in the university, and the difference between this type of care and psychotherapy. The institutional context of "Serviço de Aconselhamento Psicológico da USP" is presented; this context includes the experiences aforementioned, as well as a fictional construction of an attention history and some comments that articulate clinical background and theoretical aspects of client-centered therapy and existential phenomenology. Some aspects perceived as fundamental in the therapists' activities are emphasized, such as reception posture and the research related to client complaint; the careful observation of the way clients show up, since their arrival all the way to the final step of psychological duty; and the will to build a truthful relationship between therapist and client. Finally, the text addresses the notion of demand that is behind the proposal of psychological duty, and explores, based on the experiences of the characters involved - client, therapist and supervisor, one of the existing non-directive paradoxes, according to Max Pagés (1976), in the relation to psychological support, that is, the paradox of identification-differentiation between therapists and clients.

Keywords: Psychological duty. Psychologist education. Client centered therapy. Existential phenomenology.

Resumen: Este trabajo presenta una experiencia de guardia psicológica que presentó en su desarrollo algunas reflexiones importantes para la elaboración del sentido específico de esta modalidad en la formación del futuro psicólogo, destacándose la frontera con la psicoterapia. Se presenta el contexto institucional del Servicio de Asesoramiento Psicológico de la USP, en el cual se inserta la experiencia, junto con la narrativa del atendimiento propiamente dicho y algunos comentarios que articulan vivencia clínica y reflexiones teóricas en el ámbito del abordaje centrado en la persona y en la fenomenología existencial. Se ponen de relieve aspectos percibidos como fundamentales en el hacer del psicólogo de guardia, tales como: el sostenimiento de una postura de acogida y de investigación relacionada con los sentidos de la queja; la mirada atenta a la manera como el cliente se presenta desde su llegada, durante el transcurso y desenlace del periodo de guardia psicológica; y la disposición para crear con el cliente una relación de confianza. Por último, este texto retoma y tematiza la noción de demanda, subyacente a la propuesta de guardia, y estudia, a partir de las experiencias de las personas involucradas - cliente, psicóloga de guardia y supervisora -, una de las paradojas no directivas que se haya presente, de acuerdo con Max Pagés (1976), en la relación de ayuda psicológica: la identificación-diferenciación entre terapeuta y cliente.

Palabras clave: Guardia psicológica. Formación del psicólogo. Terapia no directiva. Fenomenología existencial. 


\section{Introdução}

O presente artigo apresenta a narrativa ficcional de um processo de plantão psicológico imaginado no Serviço de Aconselhamento Psicológico do Instituto de Psicologia da Universidade de São Paulo (SAP - IPUSP). O SAP trabalha desde 1969 com o dispositivo do plantão psicológico, fundamentado nos princípios da abordagem centrada na pessoa e na perspectiva fenomenológico-existencial.

Situado no IPUSP, propõe-se a conciliar pesquisa e aprendizagem dos alunos com atendimento à comunidade. Os alunos estagiários atendem quem procura o plantão, no momento da busca pelo serviço, sem triagem ou fila de espera. São estimulados nos alunos, além do acolhimento aos clientes, a busca de um modo próprio de atender, o ganho de autonomia e a atenção ao contexto da rede pública de serviços (Schmidt, 1999). Após os atendimentos à clientela, é oferecida aos estagiários a possibilidade da supervisão, que se configura como um espaço para elaboração da experiência dos terapeutas, dando suporte às práticas.

Segundo Rocha (2009), plantão psicológico é uma modalidade singular de atendimento, tendo marcas específicas e a ideia central de acompanhar e facilitar o processo de significação da procura por ajuda psicológica.

A partir das propostas do SAP, para além do compromisso com a experiência e o sofrimento do cliente, apresentados no relato da queixa, está em foco no plantão o modo como essa pessoa chega ao serviço, como se aproxima e se apresenta, bem como as possibilidades e vislumbres a partir dessa procura. Segundo Schmidt (1999, p. 101):

O plantão é, também, a forma encontrada de conseguir uma abertura de 360 graus para as demandas da clientela. Esta abertura, por sua vez, implica a intenção de responder à singularidade de cada demanda. Responder à demanda não é, contudo, atender à demanda. [...] Praticamente, isto se traduz pelo desencadear de um processo que, envolvendo conselheiro e cliente, promova uma ressignificação do sofrimento do cliente e uma avaliação sobre os recursos disponíveis, no SAP ou fora dele, para que o cliente seja atendido de modo o mais sintônico possível com suas necessidades.
Ainda a respeito do plantão psicológico, Rocha (2009, p. 104) acrescenta: "o plantão é uma modalidade de atendimento psicológico que se propõe a acolher as pessoas que o procuram no momento de sua angústia, auxiliando-as no esclarecimento de sua demanda". Segundo Schmidt (2004, p. 174):

Acolher refere-se, neste caso, a uma peculiar atenção para a experiência do cliente no momento em que procura ajuda, que inclui não apenas o que convencionalmente se entende por queixa, mas o modo como o cliente vive esta queixa, os recursos subjetivos e do entorno sócio-psicológico de que dispõe para cuidar de seu sofrimento, bem como as expectativas e perspectivas que se apresentam a partir da busca de auxílio.

Além dos atendimentos, a formação, tal como perspectivada no cotidiano desse serviço, compreende também um olhar para como o terapeuta se coloca, como ele próprio significa a experiência do plantão. Nesse sentido, há sempre uma conversa inicial, antes dos atendimentos propriamente ditos, entre os terapeutas estagiários e as supervisoras, na qual há espaço para cada um falar de si e de sua chegada ao plantão naquele dia, configurando um momento privilegiado de resgate do modo de estar dos plantonistas no trabalho.

A respeito da chegada do terapeuta à situação da terapia, Pompéia (2004, p. 9) diz:

Como é que o paciente aproxima a terapia? $\mathrm{E}$ como é que o terapeuta aproxima a terapia? Aproximar a terapia não se refere aqui à questão de o que leva alguém a procurar a terapia e o que leva alguém a se tornar terapeuta. Penso no que a terapia significa para o paciente quando este vai procurá-la, e no que ela significa para o terapeuta que começa a atendê-lo. Em que coloração afetiva, em que modos de afinação a terapia se instala num primeiro momento, tanto para o paciente como para o terapeuta?

Acompanhando o autor, a chegada à terapia é uma situação na qual se estabelece uma relação entre terapeuta e cliente e sempre há a presença de sentimentos. De acordo com ele, essa textura afetiva se relaciona ao conceito heideggeriano de afinação (ou disposição), segundo o qual Dasein nunca experimenta 
nada que não esteja marcado por uma disposição afetiva, de modo que a afinação é um existencial, um traço que caracteriza o Dasein em sua condição primordial.

Heidegger (1986) propõe que o ser do homem, na sua imbricação com o mundo, se apresenta como abertura de sentido, ou seja, modo de existência em que, a um só tempo, os entes que vêm ao nosso encontro são sintonizados por nós a partir de uma afinação ou disposição afetiva. Dasein, traduzida da obra do autor também como ser-aí ou ser-no-mundo (Sá \& Barreto, 2011), fala do existir como modo de ser próprio do homem, designando seu estado de abertura para outros homens que não ele e para o mundo, ser para fora (existere), sempre aberto.

Pompéia (2004, p. 12) afirma conceber a terapia como "algo que se orienta, que se realiza no aproximar progressivo de uma certa afinação" e, ainda segundo o autor, quem procura a terapia sente, de alguma forma, na condição da abertura, que sua experiência deixou de ser algo familiar, tendo transitado do âmbito da intimidade para o da intimidação. Diante disso, a proposta do terapeuta seria não lutar contra a doença do paciente, mas aproximar-se, chegar perto dele, de modo a facilitar a reconstrução desse caminho de intimidade. Nesse processo, o paciente parte de uma afinação de desabrigo e o terapeuta se inicia num "estar lançado" repleto de expectativas em relação ao desconhecido que vem ao seu encontro. A partir daí, segundo o autor:

O trabalho terapêutico caminha na direção da confiança, a afinação na qual Dasein se abre para a manifestação dos acontecimentos que se dão, que se deram e que se darão em sua história, acolhe-os e, ao mesmo tempo, se entrega à doação que tudo doa, se entrega à sua própria existência (Pompéia, 2004, p. 19).

Se na terapia o encontro com o desconhecido se coloca como desafio primeiro, que convoca o terapeuta à disposição de abertura para o novo, na proposta do plantão essa experiência se radicaliza, por dois motivos. Primeiro porque o plantonista vai ao encontro do cliente com poucas informações sobre ele - alguns dados pessoais como endereço e idade, que constam na ficha de inscrição - e eventualmente a percepção de algum colega do plantão que tenha visto ou conversado com o cliente na sala de espera. Isso, porém, pode acontecer também na chegada de um cliente à terapia. Mas, em segundo lugar, num mesmo dia de plantão é provável que cada plantonista atenda mais de uma pessoa, todas elas trazendo seu universo próprio, tocando o plantonista de modo singular.

Para além das questões de como o cliente chega e se aproxima ao buscar o serviço, também é interessante pensar em como se dá o encerramento desse processo a partir da ideia de desfecho. Segundo o autor, essa palavra tem diversos significados, sempre ligados ao conceito de final, como um final que dá sentido ao caminho do atendimento, trazendo consigo uma compreensão. No entanto, para além dessa concepção, um olhar mais detido permite perceber em todo desfecho, no momento mesmo em que se fecha, a abertura de alguma outra coisa:

"Por que chamar o fechamento de desfechamento?" É que desfecho, ao mesmo tempo que encerra, fecha, também abre alguma coisa. Todo desfecho é também necessariamente abertura. Quando ele ocorre há a realização de uma ação e nesse momento começa tudo de novo outra vez. [...] Começar de novo tem o caráter de novidade, ou seja, uma nova coisa vem se colocar quando o desfecho preenche a situação primeira (Pompéia, 2000, p. 33).

Segundo o autor, "o desfecho concretiza e efetiva uma passagem" (Pompéia, 2000, p. 33) e passagem tem em sua origem "passar", associada, por exemplo, a pontes ou portas, que ligam duas coisas, marcam o fim de uma e o início de outra, seja um ambiente que fica para trás para o acesso a outro ou o fim de uma margem e início de outra. Além disto, Pompéia destaca como a pressa distorce a passagem, deixando algo em falta no desfecho. Apenas quando há a passagem, tudo pode voltar, mas não para o mesmo lugar, permitindo que se comece tudo de novo e não outra vez.

De acordo com o autor, quando isso se dá:

Não estamos, no entanto, presos ao mito do eterno retorno. Não estamos sempre voltando ao mesmo ponto de partida. Podemos, de dentro do sofrimento e da obscuridade de um certo momento em que vivemos, olhar de novo para aquilo que 
acabamos de viver. Isto não é "des-olhar" ou "olhar para a frente". É o "olhar para trás" não esvaziando tudo que aconteceu (Pompéia, 2000, p. 39).

Nesse sentido, destaca-se a importância da ação do terapeuta no desfecho de um processo, seja ele de plantão ou psicoterapia. Na graduação em Psicologia, estamos bastante acostumados a discutir as entrevistas iniciais, o processo de psicodiagnóstico que inicia o trabalho com o paciente ou a anamnese, conforme as diferentes abordagens. O encerramento de um processo, no entanto, é tema espinhoso e, ao mesmo tempo, fundamental. Enquanto o processo terapêutico está aberto, ele pode ser ressignificado pelos atores envolvidos e ter toda a sua validade questionada, reafirmada ou descoberta, abrindo ou fechando o caminho para sua compreensão e possível continuidade futura.

Quando o que está em questão é o trabalho de plantão, esse aspecto se torna mais relevante ainda, já que a herança das práticas psicológicas, a qual recebemos e estamos reinventando cotidianamente, não reconhece como tão legítimas as modalidades que se diferenciam da psicoterapia. O plantão psicológico, entre elas, sofre preconceitos por ser visto como o início de uma psicoterapia ou como um processo de triagem, como se fosse apenas um outro nome dessas mesmas práticas. $\mathrm{Na}$ verdade, ele não se assemelha a nenhuma dessas duas vertentes, partindo de princípios inteiramente diversos. Vamos retomar essa discussão mais adiante.

É apresentada a seguir a narrativa ficcional de um atendimento de plantão psicológico. Essa contribui com elementos para se pensar sobre a chegada de clientes e terapeutas, o processo pelo qual passam juntos e o desfecho, que permitem uma significação do trabalho terapêutico. A narrativa apresentada a seguir foi construída como mosaico que reúne elementos da imaginação das autoras, inspirada em suas diversas experiências de atendimento ${ }^{1}$. Entendendo que as reflexões aqui apresentadas falam de singularidades que se comunicam com a pluralidade de experiências abrigadas no universo do plantão psicológico, optamos por fazer nosso caminho pela via da ficção. Não trazemos aqui elementos da biografia de alguém que tenha sido atendido, como é de costume nos artigos de psicologia clínica, mas nos propusemos a criar uma personagem inspirada em nossas experiências de atendimento, que são nosso verdadeiro foco aqui. Sem dizer respeito a ninguém em especial, fala de muitos dos atendimentos realizados no âmbito do SAP e, sobretudo, das marcas que nos imprimiram. Assim, na confecção dessa espécie de história inventada cuidamos de a um só tempo preservar guardado com respeito o que nos foi contado em confiança pelas pessoas que atendemos e, ao mesmo tempo, damos asas às nossas reflexões sobre o trabalho, que a partir desse vôo se aprofundam e crescem como fonte de aprendizagens.

\section{História de uma jovem com medo de animais que vem ao plantão psicológico...}

Como fazem os matutos, o que contamos agora é mais um "causo" do que um "caso". Ou, como os autores de novela, "esta é uma obra de ficção", que esperamos, sim, que guarde semelhanças com a realidade, ainda que não literais. Se a realidade se fizer notar na história, será pelo fato de ela ser nossa inescapável fonte inspiradora.

Bianca, 35 anos, chegou ao plantão contando que tinha medo de animais. Segundo ela, ele se agravou desde que mudara de residência para uma área onde vivenciava contato intenso com animais.

Ela relata à plantonista que desde pequena tem tal medo, já tendo adotado diversas estratégias para tentar melhorar, desde técnicas de exposição aos animais até evitação. Bianca diz não se lembrar de quando isso começou, mas que agora estava buscando a área da Psicologia, apesar de não acreditar que pudesse ajudar. Segundo a cliente, tinha conhecidos com sintoma semelhante que haviam feito tratamento psicoterapêutico sem resultado. Ainda assim, estava disposta a tentar uma psicoterapia, desejando ser encaminhada para um serviço especializado, a fim de se curar rapidamente.

Ao longo do plantão, plantonista e cliente foram tentando pesquisar como aparecia aquele medo que incomodava a cliente. No fundo, a tentativa era enxergar a fobia que incomodava a jovem como uma manifestação subjetiva mais ampla, mergulhando mais profundamente no incômodo que aparecia e desvelando nele os aspectos singulares constitutivos do medo de animais tal como vivido pela cliente. A terapeuta sem dúvida queria ajudar a cliente a sair daquela situação, 
o que não via como ser alcançado sem que antes houvesse alguma possibilidade de entrada em contato com o problema.

Bianca e a terapeuta giravam em círculos, falando sobre o medo que ela sentia e diversos modos e situações em que ele aparecia, bem como sobre diferentes formas de a cliente evitar o contato com animais, ainda que isso implicasse no prejuízo de tarefas diárias ou em abrir mão de coisas que gostava muito de fazer. Foram diálogos angustiantes que pareciam não levar a lugar algum.

Chamou a atenção o fato de que, assim como na vida de Bianca, o medo de animais havia dominado o atendimento, tomado conta, de modo que parecia incontornável. Não havia saída, não havia nada a fazer: as tentativas de pensar essa manifestação de uma maneira mais ampla pareciam infrutíferas. A terapeuta fazia perguntas tentando conhecer a história da queixa da cliente, desde quando se sentia daquela forma, quais tinham sido os momentos mais marcantes em relação àquela questão, no entanto, o caminho possível naquele momento foi o de falar pragmaticamente do medo e do que ele trazia, na atmosfera da busca de uma solução pontual e indolor.

Ao final do encontro de plantão, a terapeuta conversou com Bianca sobre a possibilidade de retorno, para continuarem pensando em possíveis desdobramentos da vinda da cliente ao serviço, considerando seu pedido inicial de um atendimento especializado e outras possibilidades. A cliente continuou bastante desconfiada com relação a como a Psicologia poderia ajudá-la. A impressão da terapeuta foi a de que ela gostaria de dicas e técnicas para se desvencilhar de seu medo, mas não estava muito claro se a cliente estava realmente decidida a ir por tal caminho, ainda que parecesse muito desconfiada. Bianca parecia estar apelando para si mesma, como se desse uma última cartada, já sem muitas esperanças ao procurar o SAP. Após o primeiro encontro, a terapeuta sentiu certo desânimo, achando que Bianca não voltaria na semana seguinte.

No dia em que estava marcado o retorno da cliente de fato ela não compareceu. Ao final do horário, a terapeuta foi até a sala de recados e havia uma mensagem dela, avisando que não tinha conseguido ir à sessão, mas gostaria de remarcar. Após uma ligação telefônica, o retorno foi remarcado para o dia seguinte. A terapeuta se sentiu surpresa, pois algo parecia ter feito Bianca querer voltar ao serviço, ainda que não na primeira data agendada.

Bianca compareceu no dia seguinte e contou que, após o plantão, havia pensado bastante no que tinha sido dito e havia se lembrado de algumas situações de sua infância. Segundo ela, sempre foi a filha mais reservada dos seis irmãos. Uma de suas irmãs, por exemplo, era muito bagunceira em casa, recebendo atenção dos pais, e um de seus irmãos, por outro lado, era um exímio tocador de piano, sendo motivo de destaque. Conta que sempre foi mais tímida e que havia pensado na possibilidade do enorme medo que sentia de animais ser uma forma que encontrou de chamar a atenção para si, já que desde pequena trazia-o consigo e seus pais demonstravam ter um cuidado especial com ela em algumas situações em que estava sujeita ao contato com gatos, cachorros ou outros animais, quando criança. No entanto, ainda não via sentido nessa hipótese, já que atualmente tinha suas questões familiares superadas e que, segundo ela, descobrir o que "estava por trás" de seu medo não reduzia o que sentia. A plantonista começou a perceber então que a cliente talvez quisesse receber um cuidado especial e passou a fica atenta não só a sua história de vida mas também ali, àquele encontro entre elas.

Parecia muito importante o fato de que se estava conseguindo ter abertura para uma compreensão mais rica da questão que havia mobilizado a busca por ajuda, permitindo a formulação de novas conexões pela cliente. Uma pequena onda de ânimo chegou ali com uma possibilidade de confiança no caminho que estava sendo trilhado.

Diferentemente do atendimento anterior, a sessão não estava circunscrita à resolução do medo de animais, mas, sim, disponível para outras questões importantes para ela, advindas do mergulho pela cliente no próprio medo, na companhia da terapeuta e depois sozinha com seus botões. Parecia que, enfim, mais do que dizer sobre como pensar uma queixa de modo mais amplo, isso estava sendo vivenciado, experimentado por ambas.

Ainda assim, Bianca se mostrou nervosa, argumentando que não lhe parecia servir de nada aquele modo de pensar. A terapeuta então tomou coragem e comentou sobre a sensação de ela estar apelando para si mesma 
e perguntou como era isso para ela. A cliente parou e pensou um pouco, um tanto surpresa com a colocação mais direta da terapeuta, mas achou que tinha sentido e retomou a desesperança com que havia chegado ao serviço, já tendo tido contato com outras pessoas que também sofriam com o medo de animais e que mesmo após terem feito psicoterapia, continuavam com dificuldades. Foi proposto à cliente pensar em como, de certa forma, o incômodo de que falava também não era uma espécie de apelação, algo que aparecia e pedia para ser visto e trabalhado. Algo que se mostrava e não se deixava ser ignorado. Bianca concordou, mas dizia que, de todo modo, preferia um trabalho mais diretivo, direcionado, para que pudesse saber "onde estava pisando", o que considerava muito importante em sua vida. Completou dizendo que confiava que a terapeuta saberia qual o melhor encaminhamento para ela.

A cliente parecia interessada na perspectiva diferente que a terapeuta trazia. Ao mesmo tempo, um medo, uma insegurança muito grande se faziam presentes entre elas, como se a cliente através da sua urgência mostrasse o tamanho de sua fragilidade e pedisse para ser protegida.

A terapeuta, mergulhada nessa atmosfera, compreendendo a cliente e ao mesmo tempo atenta ao seu papel e às suas possibilidades ali, naquele encontro, manifestou mais uma vez sua impressão, que naquele momento era de que a cliente parecia não estar confiante na possibilidade de encontrar uma saída para aquela situação tão angustiante. Ela, por sua vez, sentia que não tinha como saber o que era mais indicado para a cliente nem para qualquer pessoa que viesse buscar ajuda, pois acreditava que cada um de nós faz um caminho próprio, com as melhores escolhas possíveis em cada situação, de acordo com a sua própria percepção da vida. Então estava disposta a ajudar a cliente a encontrar esse caminho, mas não a dizê-lo por ela. A terapeuta se sentia lado a lado com a cliente, dividida em relação a qual poderia ser seu projeto de cuidado, já que, por um lado, elas tinham começado um rico trabalho, falando de questões mais amplas e de um modo diferente de se pensar; por outro, Bianca falava de uma necessidade de segurança e de ter clareza do caminho que trilhava, que também não poderia ser desconsiderada. A terapeuta pisava com um pé em cada canoa, vivendo na própria pele a hesitação que a cliente parecia estar sentindo.

Ao final do plantão, foi conversado com Bianca sobre seu interesse em voltar para mais um retorno, já que, caso não desejasse voltar, poderia ser encaminhada por telefone. Ela disse que também estava em dúvida após as colocações da terapeuta e que gostaria de conversar um pouco mais antes de decidir, marcando mais um retorno.

Entre um retorno e outro, a plantonista procurou sua supervisora e se viram as duas numa situação muito delicada. Como se não bastasse a encruzilhada em que já se encontrava por receber uma cliente tão angustiada, a plantonista confessou que também sentia um enorme medo de animais e se sentia perdida em relação ao que fazer, pois vivia questões muito parecidas. A supervisora, que teoricamente ancoraria as angústias da cliente e da plantonista no atendimento, por sua vez, viu-se tão perdida quanto, acometida pela mesma dificuldade. O medo de animais era algo que afligia também as duas! Ao constatarem tal fato, perceberam que isso ao mesmo tempo que tecia uma ligação intensa entre as três, muito Ihes separava também, uma vez que a aparente similaridade de suas aflições tornava nebulosa a compreensão da experiência da cliente naquele momento. Supervisora e plantonista se viram de início tomadas por algo maior que as paralisava e precisaram tomar a difícil decisão de reconhecer que naquele momento estavam cara a cara com seus próprios medos. Penetrar a primeira camada da fala da cliente só seria possível numa outra etapa, pois essa fala as havia levado para experiências mais profundas, não só suas mas humanas, que também apelavam.

Foi em outro dia, mais capazes de falar a respeito de suas sensações e preocupações, que conseguiram tratar do impacto da história da cliente sobre cada uma e começaram a garimpar as pedras preciosas em meio às paredes da caverna em que estavam lançadas.

No dia em que estava marcado o segundo retorno, quando a terapeuta chegou ao prédio 
em que ocorrem os atendimentos, havia um recado na sala, apenas avisando que Bianca não poderia vir. Não havia pedido para remarcar.

A terapeuta optou por aguardar um pouco mais para entender melhor se Bianca não queria retornar - o que, além de ser uma possibilidade, era válido - ou se, de fato, a cliente não tinha clareza a respeito do funcionamento do serviço, não tendo pedido para remarcar porque, da outra vez em que não pôde comparecer, a terapeuta lhe telefonou.

Alguns dias depois, antes de a terapeuta fazer o movimento de entrar em contato, a cliente telefonou, interessada em agendar um novo encontro. A parceria da terapeuta parecia ser importante para a cliente, em meio a tantas dúvidas e indefinições. Segundo ela, iria ao plantão naquela semana procurá-la, caso não conseguisse contato.

Logo no início da sessão, Bianca falou que havia pensado em tudo que havia sido conversado naqueles encontros e que realmente entendia a importância de compreender seu medo como uma vivência que dizia mais sobre ela mesma do que tinha podido perceber inicialmente. Relatou que pôde compreender a seu medo e a si mesma de formas diferentes após os atendimentos e que, mesmo não tendo um caminho preestabelecido, havia gostado de poder refletir de um modo mais amplo, menos estrito, podendo continuar o caminho sem as respostas ou soluções de imediato, mas com um diálogo aberto, que, por si só, já trazia um certo alívio e sensação de aconchego. A intimidação parecia ter caminhado em direção à intimidade.

Disse à terapeuta que, de fato, naquele instante se sentia interessada em iniciar um trabalho psicoterapêutico, já que estava começando a entender - e a vivenciar - essa possibilidade de, trabalhando suas questões, poder chegar, aos poucos, em seus medos, que naquele momento já não eram compreendidos estritamente como medo de animais mas medos maiores, como medo de ficar sozinha, medo de não ser vista, medo de sofrer, medo de chorar... Era como se a urgência houvesse se movimentado e transmutado em outras perspectivas, sem deixar de estar lá como algo importante.
Bianca também relatou que havia percebido como a fobia lhe dizia respeito, ainda que tão difícil de ser acolhida e compreendida, não sendo algo que vinha de fora e tomava conta dela, impedindo que fizesse o que desejava. Era uma força difícil de ser aceita, mas que lhe pertencia. Ambas se pertencendo mutuamente.

Por fim, a terapeuta comentou que, apesar de ela ter apelado para si, não apostando muito em seus últimos esforços para lidar com o problema, uma vez que Bianca havia decidido procurar o serviço, pôde se envolver no apelo de forma profunda, deixando-se levar para conexões afetivas que foram se apresentando. Foi uma mostra de como ela era capaz de se superar e amadurecer ao olhar para si mesma com confiança e acolhimento.

Encaminhando para o final da sessão, a terapeuta esclareceu a Bianca que o serviço tem parceria com alguns profissionais que recebem clientes para atendimento, considerando algumas normas, e que poderia encaminhá-la se aquela fosse sua vontade.

Após essas considerações, Bianca disse que iria viajar a trabalho por alguns meses, de modo que perderia parte significativa do período do atendimento. As duas conversaram sobre aquele movimento e levantaram a hipótese: talvez fosse um tempo de digestão do processo iniciado e acomodação em relação a um novo olhar, aberto para conhecer novas paisagens? A cliente então se despediu agradecida e seguiu viagem.

\section{Comentários}

O mosaico fictício de experiências de atendimento descrito é emblemático das aprendizagens no plantão psicológico, onde muitos atendimentos não correspondem à consagrada fórmula em que trabalho psicológico é sinônimo de psicoterapia. A partir da escrita dessa história foi possível tematizar o plantão, pensar nele como abertura e como trabalho específico que não está amarrado a qualquer outro projeto de cuidado que possa ser dele decorrente, uma questão que se coloca como fundamental na formação em Aconselhamento Psicológico. Foi possível, a partir da história de Bianca, pensar o plantão como modo de atendimento 
singular, como apontam Rocha (2009) e Schmidt (1999), voltado para o acolhimento e esclarecimento da demanda e da significação dessa experiência de busca por ajuda. Para além de sua duração indefinida e, muitas vezes, sua configuração como encontro único, foi possível ir reconhecendo, aos poucos, o espírito do plantão como postura terapêutica, mais do que um serviço, atendimento pontual ou triagem. O que caracterizou os encontros com Bianca foi a sustentação da postura de acolhimento, sobretudo nos momentos de maior indefinição e angústia. Da mesma forma como uma equipe de plantão sustenta sua disponibilidade para quem possa chegar em busca de atendimento, dentro da sala, o plantonista sustenta sua disponibilidade e abertura para a experiência do cliente, perscrutando os sentimentos, impressões, pensamentos que ocorrem nesse encontro como matéria-prima compartilhada, sem caminhos preestabelecidos.

O trabalho não se configurou como início de uma psicoterapia, o que não impediu que fosse terapêutico. Como apontado por Rocha (2009) e Schmidt (1999), aos poucos Bianca foi ressignificando sua busca por ajuda e sua experiência, tendo sido acolhida e podendo pensar nos modos de sua chegada e de relação com a queixa que trazia. Entendemos a ressignificação de uma experiência se aproximando da noção de compreensão na perspectiva fenomenológico-existencial. Compreender envolve perceber-se como autor e narrador da própria existência e da existência coletiva, não só em sentido de dar significados novos e próprios às experiências mas também e sobretudo percebendo-se já constituído em meio a uma interpretação da realidade. Desde Husserl, a tradição fenomenológica sustenta a compreensão da realidade como o encontro do homem com a realidade vivida, percebida pela consciência intencional.

Compreensão para Heidegger constitui o modo de ser próprio do homem na medida em que ele é aberto ao mundo, compreendendo o ser dos entes que se apresentam e dele próprio. $\mathrm{O}$ ser-aí, ente que nós mesmos somos, se coloca no mundo já em meio a uma compreensão, que é seu modo de estar no mundo, aberto às coisas e aos acontecimentos.
O homem enquanto abertura é um estar aberto para percepção de presença e de algo que está presente, é abertura para a coisidade. Sem esta abertura nenhuma coisa poderia aparecer partir de si [...] A abertura como a qual o homem existe é sempre abertura para a interpelação da presença de algo (Heidegger, 2009, p. 256).

Arendt (1992), por sua vez, distingue a compreensão de outras duas formas do pensar, qual sejam o pensamento propriamente dito e o conhecimento. O pensamento tem como finalidade a busca dos sentidos e significados últimos das coisas (p.e., o que é o amor, o que é a morte), questões as quais somos chamados a responder, que não são verdades disponíveis para nós. O pensamento, portanto, retira-nos do mundo e nos lança nos questionamentos em última instância irrespondíveis, questionáveis infinitamente. O conhecimento, por sua vez, é a procura de verdades permanentes e aplicáveis. São os produtos da ciência, que ficam disponíveis para uso (p.e., o que é uma molécula). A compreensão, por fim, é próxima do pensamento. Refere-se ao que faço com o que sei, como lido com o que penso/sei. Vinculada à existência cotidiana da vida viva, a compreensão é o que nos permite a reconciliação com a realidade quando essa nos convoca; ao mesmo tempo, é o que nos enlaça com o mundo na medida em que compreendemos do momento em que nascemos à nossa morte. $\mathrm{O}$ trabalho terapêutico de fundamento fenomenológico-existencial, seja ele de plantão, psicoterapia ou outra modalidade, tem como desafio favorecer a coragem necessária à descoberta da própria compreensão e do modo de ser que ela enseja.

Retomando as reflexões sobre a experiência de plantão psicológico, mais do que falar sobre o medo como parte da experiência singular do sujeito e não como algo externo que domina e impede a vida, a terapeuta e Bianca puderam vivenciar isso. Aos poucos, as sessões deixaram de ser sobre o medo como um problema a ser resolvido e passaram a ser sobre um medo que ao mesmo tempo em que assustava era ponte para as narrativas da experiência da cliente em suas conexões internas com lembranças, sentimentos, sensações e ideias sobre si mesma. Não sendo percebidos como elementos excludentes, a narrativa da queixa e as queixas da narrativa ao longo das sessões 
foram se confundindo, podendo ser vividas como figuras pertinentes a Bianca.

Como na metáfora da ponte (Pompéia, 2000), a queixa dá passagem à experiência. Se ficam apenas restritos a como solucionar o problema trazido pelo cliente, os encontros de plantão perdem sua riqueza e profundidade; no entanto, sem um interesse verdadeiro e paciente naquele mal-estar que é trazido, apelo que muitas vezes se apresenta inicialmente irremediável, ambos, cliente e plantonista, sequer iniciam o percurso das descobertas. Bianca foi podendo, aos poucos, significar, a partir de sua queixa, uma experiência que vinha se apresentando como de intimidação, se abrindo para os acontecimentos que se deram e continuam se dando em sua trajetória existencial, acolhendo-os e revivendo-os com intimidade.

Isso foi possível a partir da aproximação e da relação de confiança que foram se estabelecendo nos atendimentos, valores atrelados à equação básica das atitudes descritas por Rogers (1966) como necessárias e suficientes (congruência, empatia, aceitação positiva incondicional) para a aprendizagem, o crescimento e a mudança nas relações de ajuda.

Recentemente vem sendo incorporada à definição tradicional a perspectiva do plantão como prática de fronteira, enfatizando seu caráter de encontro entre os saberes da clientela e da equipe de plantão (Fujisaka et al., 2013). A noção de fronteira coaduna diversos elementos a partir dos quais plantão se diferencia da vertente da neutralidade ou competência superior ideologicamente associadas aos saberes científicos, já descortinadas pela tradição humanista e fenomenológica. Fala da região do encontro entre mundos diferentes que compõem um comum, no qual plantonistas e supervisores recebem os modos de viver que se apresentam, aí respeitando sua legitimidade e autonomia; e fala também do caráter de passagem que marca o sítio do encontro, chamando atenção para uma trajetória que vem vindo, chega e segue a partir dali, transformada.

Para a terapeuta, além de poder lidar com sua própria afinação e seu estar lançada, foi possível pensar em como cada cliente vai estabelecendo seu movimento próprio durante o plantão, que é sempre abertura e não fechamento, em seu modo de chegar, desenvolver e desfechar o trabalho. Além disto, em sua experiência como estagiária do SAP conseguiu ressignificar a prática do plantão psicológico, como pode se diferenciar da psicoterapia sem deixar de ser terapêutica e compreendeu melhor a importância da possibilidade dos retornos. $\mathrm{O}$ relato ficcional ilustra como esses reencontros se configuram como passagem também, permitindo o desfecho de um processo, sem pressa, e a abertura do começar de novo.

Ainda a respeito do desfecho, destaca-se o significado de Bianca ter optado por não prosseguir o trabalho em psicoterapia naquele momento: ela estava realizando sua passagem, ainda em cima da ponte citada por Pompéia (2000), nem numa margem do rio, nem na outra... A cliente estava falando de seu modo próprio de viver suas experiências e se apropriar do espaço do plantão, de modo que pode também significar sua procura por ajuda (Rocha, 2009). Depois de uma chegada aparentemente apressada, aos poucos Bianca foi podendo se aproximar da terapeuta, saindo de seu desabrigo para uma relação de mais confiança, ou também vivenciando o desabrigo da pesquisa que estava se apresentando, com mais confiança na possibilidade de ouvir seu próprio apelo. Como ensina uma parábola judaica, o dispositivo do plantão confirma que muitas vezes o caminho que parece mais longo se revela mais curto - e vice-versa (Bonder, 1998).

Além disto, também vale destacar, como cita Schmidt (1999), que a demanda de Bianca foi respondida, não tendo, necessariamente, sido atendida. Fazer a distinção entre responder e atender à demanda é fundamental, principalmente após uma breve olhada nos dicionários em que é possível dar conta do terreno rico e profundo no qual nos situamos quando estamos diante de uma "demanda": causa, litígio, pleito, disputa, discussão, procura, combate, guerra, peleja, exigência, reivindicação, confronto... Palavra polissêmica, demanda é tão plural de significados quanto são os caminhos de seu desdobramento. Seus contornos e tonalidades diversos fazem com que seja fundamental a abertura para o 
encontro com o desconhecido que nos aproxima num contexto de atendimento. Aproximar a demanda é um convite de bem conhecer, querer saber de que demanda se está falando afetivamente - uma guerra, uma exigência, uma discussão, uma peleja? - antes mesmo de refletir sobre ela, de querer transformar ou de qualquer outra coisa. Como se buscássemos compreender o que há para compreender.

Na história aqui contada, supervisora, plantonista e cliente estiveram desde o momento inicial profundamente conectadas pela queixa que se apresentava. O medo de animais foi descoberto como algo comum entre elas, por ser seu material de trabalho naquela circunstância e por ser um desafio pessoal de cada uma. O medo de animais das três personagens, reunidos num entroncamento único, levavam, todavia, a caminhos muito distintos na história pessoal de cada uma. Entretanto, só com a parada no ponto de encontro seria possível perscrutar essas diferentes estradas e perceber a abertura de sentido peculiar a cada uma. A similaridade da experiência que estava em jogo cumpriu um papel fundamental na empatia com relação à escolha da cliente ao final do processo de plantão. A diferenciação, por sua vez, permitiu a abertura para novas conexões de sentido próprias à cliente. Ambas as forças foram se equilibrando a serviço do reconhecimento da pessoa singular que estava buscando ajuda, forjando para nós a possibilidade de uma posição de vizinhança, próxima, porém não coincidente.

Com relação a esses aspectos, Pagés (1976, p. 99) apresenta um debate interessante em que, para ele, no trabalho terapêutico, a possibilidade da identificação e da diferenciação se igualam em importância. O autor convida a pensar que a possibilidade de uma relação de aceitação com o outro existe, em primeiro lugar, na aceitação das nossas próprias angústias e solidão, vínculo fundamental que nos une. Paradoxalmente, essa percepção de si, por parte do terapeuta, é o que permite a ele perceber o outro como um ser separado e sofrer seu drama, "diferente de, mas paralelo ao meu, e descobrir nossa solidariedade".

[...] se produz, no cliente, uma espécie de inversão do "movimento", que a fuga se transforma em progressão. Ela [a terapia não diretiva] aposta nesta inversão do movimento. Este é apenas o que chamaremos de paradoxo central, o fato de que a aceitação, a valorização da angústia permite ultrapassá-la. Estas angústias, estes movimentos de fuga que reconheço, aos quais atribuo valor, no momento mesmo em que os valorizo, paro de fugir diante delas pelo movimento mesmo pelo qual as reconheço, e do mesmo passo as transformo; o desespero de ser limitado pela minha individualidade, minha historicidade, minha contingência, transforma-se na consciência de estar só com os outros. Este movimento de inverso, de confrontação da angústia, é o movimento mesmo da terapia, do começo ao fim, poder-se-ia dizer que é o movimento mesmo da vida, que a terapia só faz acelerá-lo (Pagés, 1976, p. 102).

No espírito da abordagem centrada na pessoa, as experiências aqui compartilhadas falam não só de um modo de fazer clínico, situado no contexto de uma relação de ajuda profissional, mas, para além disso, de encontros humanos que se dão entre alunos, clientes e supervisoras, atravessados por qualidades facilitadoras das aprendizagens, descobertas e ressignificações trilhadas por todos os envolvidos.

A escrita deste texto é uma confirmação do quanto são importantes e mobilizadoras as experiências profissionais e pessoais vividas em plantão psicológico. A narrativa ficcional aqui articulada a guias teóricas que nos permitem enunciar o trabalho realizado de maneira enriquecedora pode e esperamos que consiga contribuir para facilitar a aproximação de outros terapeutas em formação do campo do aconselhamento psicológico. Porém, nada que chegue ao leitor com a pretensiosa intenção de prepará-lo poderá suplantar a própria experiência do fazer, que, apenas quando vivido, pode ser compreendido e aceito como desafio que jamais se acaba. 


\section{Juliana Oliveira Breschigliari}

Mestre em Psicologia pela Universidade de São Paulo, São Paulo - SP. Brasil.

E-mail: julianabreschi@gmail.com

\section{Giovana Telles Jafelice}

Graduada em Psicologia pela Universidade de São Paulo, São Paulo - SP. Brasil. Especialista em Saúde Mental pela Universidade Federal de São Paulo, São Paulo - SP. Brasil.

E-mail: gi_jafelice@yahoo.com.br

Endereço para envio de correspondência:

Av. Prof. Mello Moraes, 1721, bloco D. Cidade Universitária. CEP 05508-030 - São Paulo, SP - Brasil.

Recebido 13/01/2014, Aprovado 18/11/2014. 
Arendt, H. (1992). A vida do espírito. Rio de Janeiro: Relume Dumará: Ed. UFRJ.

Benjamin, W. (1989). Sobre alguns temas em Baudelaire. In W. Benjamin, Charles Baudelaire: um lírico no auge do capitalismo (Obras Escolhidas, Vol. 3, pp. 103-149). São Paulo: Brasiliense.

Benjamin, W. (1994). O narrador: considerações sobre a obra de Nikolai Leskov. In W. Benjamin, Magia e técnica, arte e política (Obras Escolhidas, Vol. 1, pp. 197-221). São Paulo: Brasiliense.

Bonder, N. (1998). O longo caminho curto x o curto caminho longo. In N. Bonder, A alma imoral: traição e tradição através dos tempos (pp. 57-58). Rio de Janeiro: Rocco.

Fujisaka, A. P., Breschigliari, J., Rocha, M. C., Eisenlohr, M. G., Kovács, M. J., \& Schmidt, M. L. (2013). Plantão psicológico em centroescola: tradição, reinvenção e rupturas. In M. Tassinari, A. P. Silveira \& W. Durange (Orgs.), Revisitando o plantão psicológico centrado na pessoa (pp. 61-82). Curitiba: CRV.

Heidegger, M. (1986). El ser y el tiempo. México: Fondo de Cultura Económica.

Heidegger, M. (2009). Seminários de Zollikon. Petrópolis: Vozes; Bragança Paulista: Editora Universitária São Francisco.
Pagés, M. (1976). Orientação não-diretiva em psicoterapia e psicologia social. Rio de Janeiro: Forense-Universitária; São Paulo: EDUSP.

Pompéia, J. A. (2000). Desfecho: encerramento de um processo. Associação Brasileira de Daseinsanalyse, 9, 31-43.

Pompéia, J. A. (2004). Aspectos emocionais da Terapia Daseinsanalítica. Associação Brasileira de Daseinsanalyse, 13, 5-20.

Rocha, M. C. (2009). Plantão psicológico: desafios e potencialidades. In J. O. Breschigliari \& M. C. Rocha, Serviço de aconselhamento psicológico: 40 anos de história (pp. 103-120). São Paulo: Instituto de Psicologia: SAP.

Rogers, C. (1966). Psicoterapia centrada en el cliente. Buenos Aires: Paidós.

Sá, R. N., \& Barreto, C. (2011). A noção fenomenológica de existência e as práticas psicológicas clínicas. Estudos de Psicologia (Campinas), 28(3), 389-394.

Schmidt, M. L. S. (1999). Positivismo lógico e pensamento existencial: a conciliação rogeriana. In H. T. P. Morato, Aconselhamento psicológico centrado na pessoa: novos desafios (pp. 107115). São Paulo: Casa do Psicólogo.

Schmidt, M. L. S. (2004). Plantão psicológico, universidade pública e política de saúde mental. Estudos de Psicologia (Campinas), 21(3), 173-192. 